\title{
Facile synthesis of an ultramicroporous MOF tubular membrane with selectivity towards $\mathrm{CO}_{2} \dagger$
}

\author{
Sonia Aguado, ${ }^{a}$ Charles-Henri Nicolas, ${ }^{a}$ Virginie Moizan-Baslé, ${ }^{b}$ Carlos Nieto, ${ }^{c}$ \\ Hedi Amrouche, ${ }^{c}$ Nicolas Bats, ${ }^{b}$ Nathalie Audebrand ${ }^{d}$ and David Farrusseng ${ }^{* a}$
}

Received (in Montpellier, France) 27th August 2010, Accepted 8th October 2010

DOI: $10.1039 / \mathrm{conj00667j}$

\begin{abstract}
A substituted imidazolate-based MOF (SIM-1) membrane has been crystallized in situ on a tubular asymmetric alumina support that can be exploited for gas separation through preferential adsorption.
\end{abstract}

For gas separation and solvent pervaporation, the manufacture of crystalline porous membranes is of prime interest. ${ }^{1,2}$ Although the synthesis of several zeolite membranes (including AlPO and SAPO) supported on porous ceramic bodies is now well established, ${ }^{3}$ the synthesis of new, defect-free crystalline molecular sieve membranes remains a challenge. Metal Organic Frameworks (MOFs) exhibiting tunable pore size $\mathrm{e}^{4,5}$ are appealing new candidates for separation using membrane processes. $^{6,7}$

Although the synthesis of supported thin MOF films has progressed rapidly, ${ }^{8}$ permeance data of a single gas on MOF membranes are scarce. ${ }^{9-12}$ In addition, only Bux et al. ${ }^{9} \mathrm{Li}$ et al. $^{11}$ and Venna and Carreon ${ }^{13}$ report effective separation greater than the Knudsen factor under mixture conditions.

Recently, Gascón and Kapteijn addressed the perspectives and current limitations of supported MOF membranes. ${ }^{6}$ The major technological hurdle limiting the application of MOF membranes in chemical processes is the development of a manufacture process of tubular membranes that is reproducible and that can be implemented on a large scale. Currently, surface pre-treatment or seeding procedures combined with secondary growth are technical solutions for achieving supported MOF membranes with good polycrystallinepacking and attachment to the support. ${ }^{11,13}$ This multi-step

${ }^{a}$ IRCELYON, University Lyon, CNRS. 2, Av. Albert Einstein, Villeurbanne, F-69626, France.

E-mail: david.farrusseng@ircelyon.univ-lyon1.fr;

Fax: + 33(4)72445399

${ }^{b}$ IFP, Physics and Analysis division BP3, Solaize, F-69360, France

${ }^{c}$ IFP, New Energy, Thermodynamic and Molecular Simulation

Department, $1 \& 4$, Av. de Bois-Préau, Rueil-Malmaison, F-92852, France

${ }^{d}$ Sciences Chimiques de Rennes (UMR 6226) University Rennes 1, CNRS 263, Av. du Général Leclerc, Rennes, F-35042, France

$\dagger$ Electronic supplementary information (ESI) available: Synthesis and characterization of SIM-1, TGA and gas sorption analysis of SIM-1, and permeance data of membranes. See DOI: 10.1039/ c0nj00667j synthesis procedure is, however, not favorable for scale-up. More recently, Bux et al. has prepared ZIF-8 membrane on titania porous support by microwave techniques, which clearly shows molecular sieving properties. ${ }^{9}$ Again, the scale-up of this technology for tubular membranes is still questionable, as is also the case for zeolite membranes., ${ }^{2,14}$ Among open questions raised by Gascón and Kapteijn, ${ }^{6}$ the effects of smaller pore size and the functionalization of the framework with pending groups on gas separation and also on catalysis appear to be very critical.

Here, we report a very reproducible one-step process operating at atmospheric pressure to prepare thin MOF membranes on a long tubular support, which meets the first criterion enabling the scale-up for the preparation of large surface of membranes. The second achievement of this work is the effective $\mathrm{CO}_{2} / \mathrm{N}_{2}$ separation under mixture and humid conditions. With respect to ZIF-7 and ZIF-8 membranes, this breakthrough result is obtained by combining a polar and bulkier linker resulting in a novel imidazolate-based MOF. ${ }^{15}$

The new solid (hereafter called SIM-1, Substituted Imidazolate Material) consists of $\mathrm{ZnN}_{4}$ tetrahedra linked by carboxylimidazolate (Fig. 1). ${ }^{15}$ It belongs to the class of ZIF or ZMOF materials. ${ }^{4,16-18}$ It is isostructural to $\left[\mathrm{Zn}(\mathrm{mim})_{2} \cdot \mathrm{H}_{2} \mathrm{O}\right]^{19}$ and $\left[\mathrm{Zn}(\mathrm{bim})_{2} \cdot \mathrm{H}_{2} \mathrm{O}\right]^{20}$ (hereafter called $\mathrm{ZIF}-8, \mathrm{ZIF}-7$, respectively). In contrast to ZIF-8, SIM-1 has no group in position 2 of the imidazolate linkers, whereas it contains a methyl and an aldehyde in position 4 and 5; the latter conferring a polar features due to the dipolar moment of the $\mathrm{C}=\mathrm{O}$ bond. Pattern indexing was carried out from $\mathrm{X}$-ray

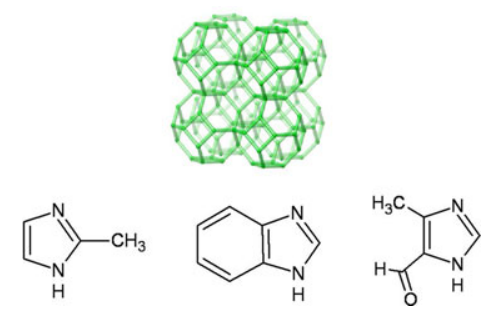

Fig. 1 Schematic drawing of the frameworks of sodalite and imidazolate linkers methylimidazole (ZIF-8), benzimidazole (ZIF-7), 4-methyl-5-imidazolecarboxaldehyde (SIM-1). 
powder diffraction data with the first 20 lines on the basis of a cubic solution, with the figures of merit $M_{20}=49$ and $F_{20}=65(0.005,60)$. A least-squares refinement on the resolved diffraction lines available led to the unit-cell dimensions $a=16.743(5) \AA$ et $V=4693.9 \AA^{3}$ (ESI $\dagger$ ). The porous structure was further studied by combining molecular modeling (VASP calculations) and Rietveld refinement. The full description of the crystal structure determination is the subject of an upcoming communication. The simulation indicates a pore size of the sodalite cavity of $8.0 \AA$ for SIM-1 against $11.3 \AA$ for ZIF-8 (11.6 $\AA$ from crystal data from ref. 18). Therefore, the size and the shape of the functionalized imidazolate linker make the sodalite cavity much smaller for SIM-1. This result is in agreement with $\mathrm{N}_{2}$ adsorption isotherm measurements at $77 \mathrm{~K}$. First, SIM-1 exhibits a much smaller micropore volume of $0.19 \mathrm{~cm}^{3} \mathrm{~g}^{-1}$, compared to $0.44 \mathrm{~cm}^{3} \mathrm{~g}^{-1}$ for ZIF-8. ${ }^{20}$ Second, low pressure adsorption data indicates an $\mathrm{N}_{2}$ uptake starts at $p / p_{0}=10^{-7}$ for SIM-1, whereas for ZIF-8 the uptake starts at pressure of 3 orders of magnitude higher. Although, the pore size estimation using DFT method embedded in ASAP $2010 \mathrm{M}^{\mathrm{TM}}$ (Micromeritics) is not valid since the hypothesis are based on oxide type surfaces and cylindrical pore type; it also indicates smaller pore size for SIM-1.

Asymmetric $\alpha$-alumina tubes ( $10 \mathrm{~mm}$ outer diameter, $7 \mathrm{~mm}$ inner diameter, $15 \mathrm{~cm}$ length, top layer pore size $200 \mathrm{~nm}$ ) supplied by Pall Exekia were used as supports for the synthesis of the membranes. Prior to synthesis, the external surface of the tubular support was wrapped with Teflon tape. The tube was then immersed in a vial of synthesis solution containing $0.71 \mathrm{~g}(2.73 \mathrm{mmol})$ of $\mathrm{Zn}\left(\mathrm{NO}_{3}\right)_{2} \cdot 4 \mathrm{H}_{2} \mathrm{O}, 1.20 \mathrm{~g}(10.94 \mathrm{mmol})$ of 4-methyl-5-imidazolecarboxaldehyde and $20 \mathrm{ml}$ of DMF. The synthesis is carried out at $358 \mathrm{~K}$ for $72 \mathrm{~h}$, the resulting membrane was washed with ethanol and dried at room temperature. In summary, the synthesis conditions are similar to the seminal works from the groups of Chen, ${ }^{19}$ Eddaoudi $^{17}$ and Yaghi, ${ }^{18}$ except the presence of the alumina tube in the synthesis media. Unsupported powders of SIM-1 were synthesized in order to characterize their intrinsic structure and adsorption properties. ${ }^{21}$

Powder XRD measurements of the composite SIM-1/ alumina membrane were carried out by crushing the supported membrane in a mortar. The diffractogram clearly shows the signals of both the SIM-1 and the alumina (Fig. 2). From the

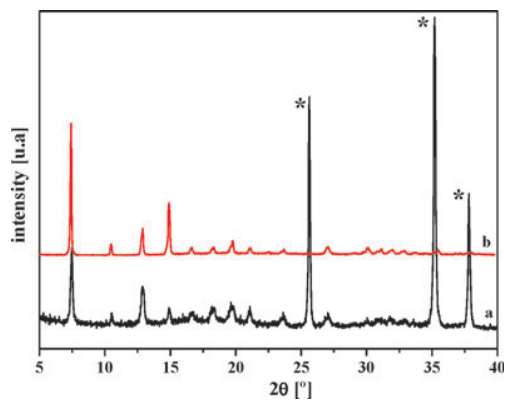

Fig. 2 XRD patterns of (a) alumina-supported SIM-1 and (b) as-synthesized SIM-1. Reflections marked by * correspond to the alumina support.

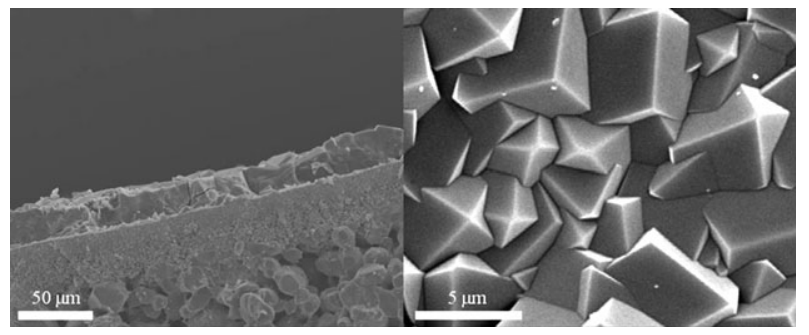

Fig. 3 SEM image of the cross-section (left) and surface (right) of the membrane.

surface view, it can clearly be seen that the SIM-1 crystals merge compactly, providing no room for gas molecules to by-pass the diffusion through the SIM-1 layer. Fig. 3 shows a cross-section view at low magnification, proving the absence of defects over a long distance. The thickness of about $25 \mu \mathrm{m}$ is uniform along the membrane. Note that thinner membranes have been obtained on different alumina supports (not shown). Finally, we can observe excellent attachment of the SIM-1 top layer to the porous support. Investigations on the alumina/SIM-interface can be found elsewhere. ${ }^{22}$

The SIM-1 membranes were tested in a single gas permeance setup with $\mathrm{H}_{2}, \mathrm{CO}_{2}, \mathrm{~N}_{2}$ and $\mathrm{CH}_{4}$ using the Wicke-Kallenbach technique. Single permeances calculated from the volumetric flow rates through the SIM-1 membrane are presented in Fig. 4. Permeance data are in the range of those of Bux et al. for a ZIF-8 membrane. ${ }^{9}$ The reproducibility of permeation results is validated on three membranes, which shows that the synthesis method is robust (Table S4, ESI $\dagger$ ). Note that without ethanol washing, no gas permeance is observed. This fact is a direct proof of the absence of defects such as holes or cracks. Ethanol washing allows the liberation of DMF molecules that are present in the cavities and that prevent gas permeance. ${ }^{9}$

Permeances of $\mathrm{CO}_{2}$ are in agreement with previous reports, ${ }^{9,11,12}$ with the exception of the work of Venna and Carreon $^{13}$ where permeances reported are 1000 times higher. In the latter work, however, the $\mathrm{CO}_{2}$ adsorption capacity of ZIF-8 is about 2-3 times larger than those found by our group and by others. ${ }^{23,24}$

Ideal selectivity data calculated from single gas permeances at $303 \mathrm{~K}$ is deviated bit from Knudsen values for $\mathrm{H}_{2} / \mathrm{N}_{2}=2.5$ (3.7) but is reversed for $\mathrm{CO}_{2} / \mathrm{N}_{2}=1.1(0.78)$ thus indicating

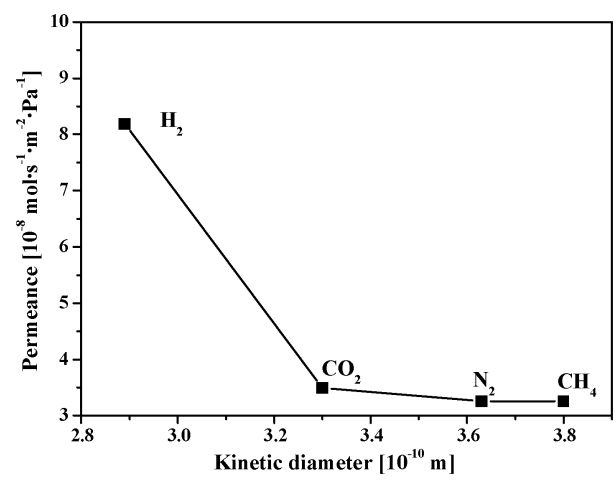

Fig. 4 Single gas permeances (at $303 \mathrm{~K}$ ) for a SIM-1 membrane as a function of the kinetic diameters. 


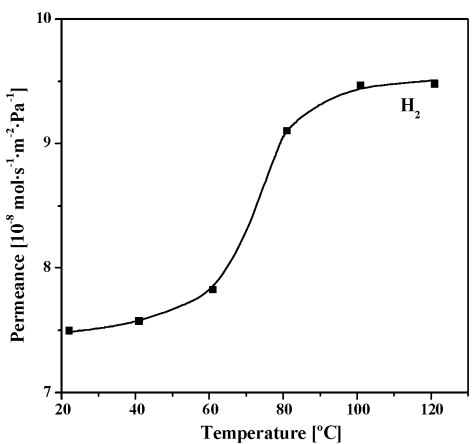

Fig. $5 \mathrm{H}_{2}$ permeance for a SIM-1 membrane as a function of the temperature.

an adsorption-diffusion based mechanism. The permeance as a function of temperature was investigated to further characterize the transport mechanism (Fig. 5). At low temperature range, permeance profiles as a function of the temperature correspond to an activated transport mechanism such as that found for microporous membranes. Viscous and Knudsen permeation mechanisms are both characterized by a decrease of the permeance as function of the temperature and therefore can be ruled out. No cracks occur upon heating up to $393 \mathrm{~K}$ (higher temperatures were not investigated). Moreover, these SIM-1 membranes show no change in permeance data and no degradation during testing for more than a month with several temperature cycles, contrary to HKUST-1 films, in which cracks reportedly develop. $^{25}$

For the ternary mixture $\mathrm{CO}_{2} / \mathrm{N}_{2} / \mathrm{H}_{2} \mathrm{O} \quad(10 / 87 / 3$ vol $\%$, $324 \mathrm{~K}, 4$ bar and $\Delta P$ of 40 mbar), a $\mathrm{CO}_{2} / \mathrm{N}_{2}$ separation factor of 4.5 is measured, which is much higher than the corresponding Knudsen separation factor (0.78). Thus under mixture conditions, a much larger preferential permeance of $\mathrm{CO}_{2}\left(\right.$ vs. $\left.\mathrm{N}_{2}\right)$ is obtained with respect to single permeance results. Similar selectivities have been obtained with MFI zeolite membranes. ${ }^{26}$ It shall be noted that much higher selectivity values have been reported for $\mathrm{CO}_{2} / \mathrm{N}_{2}$ separation on zeolite membranes, such as with DDR membranes, ${ }^{27}$ but usually in dry conditions. In addition, SAPO-34 membranes are reported to have the highest performance; with selectivity around $150 .{ }^{28}$ Nevertheless, the observed results on SIM-1 membrane demonstrate that the transport mechanisms are similar to those of zeolite membranes. Clearly, surface transport takes place in the SIM-1 membrane, which allows the separation of gases by preferential adsorption, with the most-adsorbed component reducing the diffusion of other molecules.

Adsorption measurements on SIM-1 powder support our hypothesis (Fig. S4, ESI $\dagger$ ). The heat of adsorption of $\mathrm{CO}_{2}$ on SIM-1 ( $-33 \mathrm{~kJ} \mathrm{~mol}^{-1} ;-20 \mathrm{~kJ} \mathrm{~mol}^{-1}$ for $\mathrm{N}_{2}$ ) is high enough to allow preferential adsorption (calculated selectivity of $15 \pm 1$ based on Henry constants), but too low to provide a high separation factor such as that found with zeolite membranes. Our hypothesis is also supported by recent molecular modeling work on $\mathrm{CO}_{2}$ capture in MOFs by Snurr et al. ${ }^{24}$ and MOF membranes by Keskin and Sholl. ${ }^{29}$ The first clearly shows that the adsorption heat of $\mathrm{CO}_{2}$ is the key factor to capture $\mathrm{CO}_{2}$. In contrast to SIM-1 membrane, no real $\mathrm{CO}_{2} / \mathrm{N}_{2}$ separation can be achieved on ZIF-8 membranes. ${ }^{9}$ This is due to the very low heat of adsorption of $\mathrm{CO}_{2}$ in $\mathrm{ZIF}-8\left(-18 \mathrm{~kJ} \mathrm{~mol}{ }^{-1}\right.$ for $\left.\mathrm{CO}_{2}\right){ }^{24}$

This work clearly indicates that the direct functionalization of MOFs with polar groups associated with a reduction of pore size is an efficient design enabling gas separation in membrane processes. Among MOF membranes, the SIM-1 membrane displays the highest $\mathrm{CO}_{2} / \mathrm{N}_{2}$ separation in humid conditions, although higher separation factors and higher fluxes are required to meet industrial objectives. We have also described a reproducible procedure for synthesizing tubular membranes that could be extrapolated to larger scale and to other tubular substrates with a greater surface-volume ratio. We believe that this discovery may open new opportunities in pervaporation and nanofiltration processes.

\section{Experimental}

\section{X-Ray diffraction (XRD)}

For indexing, high-quality powder diffraction data was obtained at room temperature employing a Panalytical X'Pert Pro diffractometer with Debye-Scherrer geometry. The pattern was scanned in the range $2 \theta=5-100^{\circ}$ with a step length of $0.008^{\circ}(2 \theta)$ and a counting time of $2000 \mathrm{~s}$ per step. The X'Pert Pro system is equipped with a hybrid monochromator (combination of a parabolic multilayer mirror and a 2-crystal $\mathrm{Ge}(220)$ monochromator) producing a monochromatic $\mathrm{Cu}-\mathrm{K} \alpha_{1}$ radiation $(\lambda=1.5406 \AA)$, and a position sensitive detector ( $\mathrm{X}^{\prime}$ Celerator). Pattern indexing was performed with the program DICVOL91 in the Accelrys software suite, Materials Studio 5.0.

\section{Single gas permeation}

Single gas $\left(\mathrm{N}_{2}, \mathrm{H}_{2}, \mathrm{CO}_{2}\right.$; Air Liquide; quality, 99.9999\%) permeation tests were carried out in the temperature range 304-393 K using steady-state steps to assess for the temperature behavior of the nanocomposite material. For single gas permeation, the membranes were mounted in dead-end configuration module using flat gaskets pressed onto the enamelled tube ending cross-section. Permeances were measured in dead-end configuration varying transmembrane pressure from 0.5 to 3 bar, and temperatures from 304 to $393 \mathrm{~K}$ to evaluate the presence of defects or cracks.

\section{Binary permeation}

For the mixed gas measurements feed was constant with a total volumetric flow rate of $300 \mathrm{ml} \mathrm{min} \mathrm{m}^{-1}$ with a composition $10 \mathrm{vol} \%$ of $\mathrm{CO}_{2}$ and $87 \mathrm{vol} \%$ of $\mathrm{N}_{2}$, with a $3 \mathrm{vol} \%$ of water. The pressure in the feed was constant at 4 bar, and the pressure difference with the permeate side was 40 mbar. The measurements were made at room temperature (304 K).

\section{Acknowledgements}

The authors are grateful for the financial support of MECAFI (ANR-07-PCO2-003) funded by the French National Research Agency (ANR). 


\section{Notes and references}

1 (a) A. Burggraaf and L. Cot, Fundamentals of Inorganic Membrane Science and Technology, Elsevier, Amsterdam, 1996; (b) E. E. McLeary, J. C. Jansen and F. Kapteijn, Microporous Mesoporous Mater., 2006, 90, 198-220; (c) M. Noack and J. Caro, in Handbook of Porous Solids, ed. F. Schüth, K. Sing and J. Weitkamp, 2002, pp. 2433-2507; (d) R. D. Noble and S. Stern, Inorganic Membranes-Synthesis, Characteristics and Applications, Elsevier, Amsterdam, 1995.

2 J. Caro, M. Noack and P. Kölsch, Adsorption, 2005, 11, 215-227.

3 J. Caro, M. Noack, P. Kölsch and R. Schäfer, Microporous Mesoporous Mater., 2000, 38, 3-24.

4 R. Banerjee, H. Furukawa, D. Britt, C. Knobler, M. O'Keeffe and O. M. Yaghi, J. Am. Chem. Soc., 2009, 131, 3875-3877.

5 (a) J. H. Cavka, S. r. Jakobsen, U. Olsbye, N. Guillou, C. Lamberti, S. Bordiga and K. P. Lillerud, J. Am. Chem. Soc., 2008, 130, 13850-13851; (b) X. Lin, J. Jia, X. Zhao, M. Thomas, A. J. Blake, G. S. Walker, N. R. Champness, P. Hubberstey and M. Schröder, Angew. Chem., Int. Ed., 2006, 45, 7358-7364; (c) N. L. Rosi, J. Kim, M. Eddaoudi, B. L. Chen, M. O'Keeffe and O. M. Yaghi, J. Am. Chem. Soc., 2005, 127, 1504-1518; (d) K. Seki and W. Mori, J. Phys. Chem. B, 2002, 106, 1380-1385; (e) A. C. Sudik, A. R. Millward, N. W. Ocking, A. P. Cote, J. Kim and O. M. Yaghi, J. Am. Chem. Soc., 2005, 127, 7110-7117; $(f)$ S. Surble, F. Millange, C. Serre, T. Duren, M. Latroche, S. Bourrelly, P. L. Llewellyn and G. Ferey, J. Am. Chem. Soc., 2006, 128, 14889-14896.

6 J. Gascon and F. Kapteijn, Angew. Chem., Int. Ed., 2010, 49, 1530-1532.

7 D. Zacher, O. Shekhah, C. Woll and R. A. Fischer, Chem. Soc. Rev., 2009, 38, 1418-1429.

8 (a) E. Biemmi, C. Scherb and T. Bein, J. Am. Chem. Soc., 2007, 129, 8054-8055; (b) S. Hermes, F. Schroder, R. Chelmowski, C. Woll and R. A. Fischer, J. Am. Chem. Soc., 2005, 127, 13744-13745; (c) M. Kubo, W. Chaikittisilp and T. Okubo, Chem. Mater., 2008, 20, 2887-2889; (d) C. Scherb, A. Schödel and T. Bein, Angew. Chem., Int. Ed., 2008, 47, 5777-5779; (e) E. Biemmi, A. Darga, N. Stock and T. Bein, Microporous Mesoporous Mater., 2008, 114, 380-386; (f) Y. Yoo and H. K. Jeong, Chem. Mater., 2008, 2441-2443.

9 H. Bux, F. Liang, Y. Li, J. Cravillon, M. Wiebcke and J. Caro, J. Am. Chem. Soc., 2009, 131, 16000-16001.

10 H. Guo, G. Zhu, I. J. Hewitt and S. Qiu, J. Am. Chem. Soc., 2009, 131, 1646-1647.

11 Y. Li, F. Liang, H. Bux, A. Feldhoff, W. Yang and J. Caro, Angew. Chem., Int. Ed., 2010, 49, 548-551.
12 R. Ranjan and M. Tsapatsis, Chem. Mater., 2009, 21, $4920-4924$.

13 S. R. Venna and M. A. Carreon, J. Am. Chem. Soc., 2010, 132 , 76-78.

14 J. Caro and M. Noack, Microporous Mesoporous Mater., 2008 , 115, 215-233.

15 D. Farrusseng, S. Aguado and J. Canivet, FR09/04488, 2009.

16 (a) R. Banerjee, A. Phan, B. Wang, C. Knobler, H. Furukawa, M. O'Keeffe and O. M. Yaghi, Science, 2008, 319, 939-943; (b) A. Phan, C. J. Doonan, F. J. Uribe-Romo, C. B. Knobler, M. O'Keeffe and O. M. Yaghi, Acc. Chem. Res., 2010, 43, $58-67$.

17 Y. Liu, V. C. Kravtsov, R. Larsen and M. Eddaoudi, Chem. Commun., 2006, 1488-1490.

18 B. Wang, A. P. Cote, H. Furukawa, M. O'Keeffe and O. M. Yaghi, Nature, 2008, 453, 207-212.

19 X. Huang, Y. Lin, J. Zhang and X. Chen, Angew. Chem., Int. Ed., 2006, 45, 1557-1559.

20 K. S. Park, Z. Ni, A. P. Cote, J. Y. Choi, R. D. Huang, F. J. Uribe-Romo, H. K. Chae, M. O'Keeffe and O. M. Yaghi, Proc. Natl. Acad. Sci. U. S. A., 2006, 103, 10186-10191.

21 D. Farrusseng, S. Aguado, C. H. Nicolas, B. Siret and S. Durecu, FR09/04489, 2009.

22 S. Aguado, J. Canivet and D. Farrusseng, Chem. Commun., 2010, 7999.

23 (a) S. Reyes, J. Santiesteban, Z. Ni, C. Paur, P. Kortunov, J. Zengel and H. Deckman, US, 2009/0214407; (b) J. PérezPellitero, A. H., F. Siperstein, G. Pirngruber, C. Nieto-Draghi, G. Chaplais, A. Simon-Masseron, D. Bazer-Bachi, D. Peralta and N. Bats, Chem.-Eur. J., 2010, 16, 1560-1571.

24 A. Yazaydin, R. Q. Snurr, T.-H. Park, K. Koh, J. Liu, M. D. LeVan, A. I. Benin, P. Jakubczak, M. Lanuza, D. B. Galloway, J. J. Low and R. R. Willis, J. Am. Chem. Soc., 2009, 131, 18198-18199.

25 J. Gascon, S. Aguado and F. Kapteijn, Microporous Mesoporous Mater., 2008, 113, 132-138.

26 M. P. Bernal, J. Coronas, M. Menéndez and J. Santamaría, AIChE J., 2004, 50, 127-135.

27 J. van den Bergh, W. Zhu, J. Gascon, J. A. Moulijn and F. Kapteijn, J. Membr. Sci., 2008, 316, 35-45.

28 (a) M. A. Carreon, S. G. Li, J. L. Falconer and R. D. Noble, J. Am. Chem. Soc., 2008, 130, 5412-5413; (b) S. Li, J. L. Falconer and R. D. Noble, J. Membr. Sci., 2004, 241, 121-135; (c) S. Li, J. L. Falconer and R. D. Noble, Adv. Mater., 2006, 18, 2601-2603; (d) J. C. Poshusta, V. A. Tuan, J. L. Falconer and R. D. Noble, Ind. Eng. Chem. Res., 1998, 37, 3924-3929.

29 S. Keskin and D. S. Sholl, Langmuir, 2009, 25, 11786-11795. 